\title{
A facile preparation of a novel non- leaching antimicrobial waterborne polyurethane leather coating functionalized by quaternary phosphonium salt
}

\author{
Chunhua Wang ${ }^{1}$, Jianhui $\mathrm{Wu}^{1}$, Li Li ${ }^{1}$, Changdao $\mathrm{Mu}^{2^{*}}$ and Wei Lin ${ }^{1 *}$ (i)
}

\begin{abstract}
The aim of this research is to develop a novel non-leaching antimicrobial waterborne polyurethane (WPU) leather coating material with covalently attached quaternary phosphonium salt (QPS). The structure of the QPS-bearing WPU has been identified, and their thermal stability, mechanical property, and antimicrobial performance have been investigated. The results reveal that the incorporation of QPS slightly reduces the thermal stability of WPU material but would not affects its usability as leather coating. Despite the presence of hydrophobic benzene in QPS structure, the strong hydration of its cationic groups leads to the increased surface contact angle (SCA) and water absorption rate (WAR) of the films, suggesting that the water resistance of the films needs to be improved for the purpose of leather coatings. Antibacterial tests demonstrate that when the QPS content is $20 \mathrm{wt} \%$, QPS-bearing WPU shows effective antimicrobial activity against bacteria. The WPU containing QPS prepared in this study is a non-leaching antimicrobial material and has great potential application as leather coating.
\end{abstract}

Keywords: Polyurethane, Leather coating, Quaternary phosphonium salt, Non-leaching, Antimicrobial

\section{Introduction}

Natural leather possesses unique properties such as breathability and durability and has also been widely used as a popular material for fashion items, furniture and healthcare and hospitality facilities. However, leather is a protein-based material and has been found to be susceptible to microbial deterioration, resulting in staining and decreased durability of leather products [1]. In addition, many hygiene-related diseases caused by microorganisms on product surfaces may pose potential health threats to consumers [1]. The use of antibacterial polymer coatings for leather finishing is considered as a common method to endow the leather with antibacterial performance. Waterborne polyurethane (WPU) is widely-used for leather finishing due to its

\footnotetext{
* Correspondence: cdmu@scu.edu.cn; wlin@scu.edu.cn

${ }^{2}$ Department of Pharmaceutics and BioengineeringSchool of Chemical Engineering, Sichuan University, Chengdu 610065, China

'Department of Biomass and Leather Engineering, Key Laboratory of Leather Chemistry and Engineering of Ministry of Education, Sichuan University, Chengdu 610065, China
}

excellent overall properties [1]. As for antibacterial polyurethane (PU) leather coating, the conventional strategy is to mix chemicals biocides such as chlorinated phenols, dimethylfumarate, 2-(thiocyanomethylthio) benzothiazole with the polymers [2]. Despite their excellent efficiency in killing microorganisms, those biocides are becoming unacceptable [3] and some of them have been restricted or even prohibited because of high toxicity and ecological hazards [4]. The easy leaching of the physically-incorporated biocides from the coating not only brings about adverse effects on environment and human health, but also compromises their long-term effectiveness [1]. The covalent bonding of antimicrobial moiety to polymer matrix can avoid the permeation problems [5]. Therefore, non-leaching antimicrobial leather coatings are high desirable as an environmentally friendly option [6].

In the last decades, quaternary ammonium salts (QAS, cationic) have been intensively investigated for their highly efficient antimicrobial activity, broad-spectrum and low toxicity [7]. Recently, with structures and 

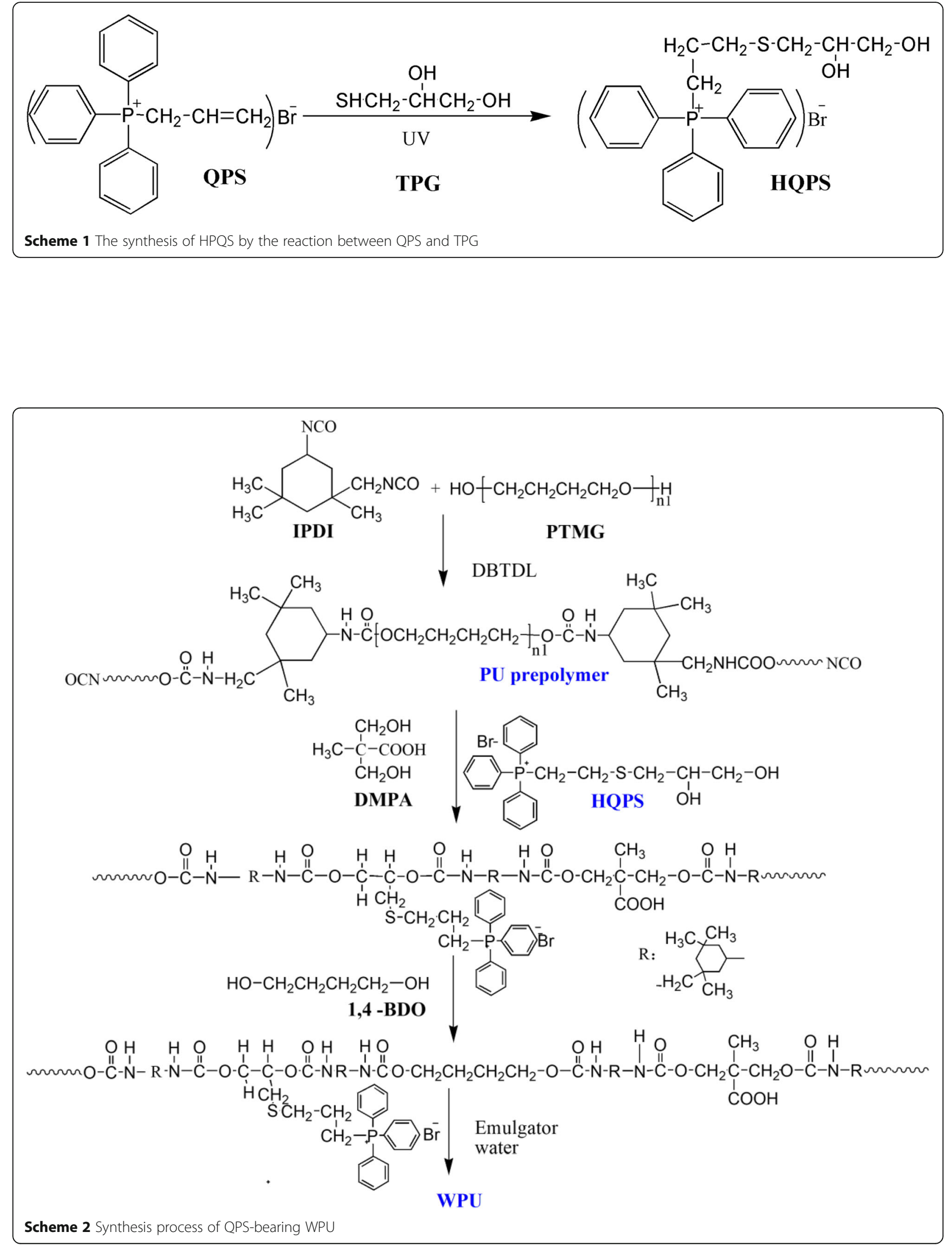
Table 1 Formulations and characteristics of WPU

\begin{tabular}{|c|c|c|c|c|c|c|}
\hline Sample & $\begin{array}{l}\mathrm{PTMG} / \mathrm{IPDI} / \mathrm{DMPA} / \\
\mathrm{HQPS} / 1,4-\mathrm{BDO}^{\mathrm{a}}\end{array}$ & $\begin{array}{l}\text { DMPA } \\
\text { (wt\%) }\end{array}$ & HQPS (wt\%) & Mean size $(\mathrm{nm})$ & PDI & $\begin{array}{l}\mathrm{HS} \\
(\mathrm{wt} \%)\end{array}$ \\
\hline WPU-0 & 1: $7: 2.19: 0: 3.81$ & 7 & $0 \%$ & 28.2 & 0.14 & 52.3 \\
\hline WPU-5 & 1: $7: 2.30: 0.45: 3.52$ & 7 & $5.0 \%$ & 31.7 & 0.19 & 54.3 \\
\hline WPU-10 & 1: 7: 2.40: 0.93: 2.67 & 7 & $10.0 \%$ & 40.6 & 0.11 & 55.8 \\
\hline WPU-15 & 1: $7: 2.50: 1.46: 2.04$ & 7 & $15.0 \%$ & 54.6 & 0.08 & 57.6 \\
\hline WPU-20 & 1: $7: 2.63: 2.05: 1.32$ & 7 & $20.0 \%$ & 80.6 & 0.09 & 59.5 \\
\hline
\end{tabular}

${ }^{\mathrm{a}}$ Feed molar ratio

property similar to QAS, quaternary phosphonium salts (QPS) have been developed presenting new progress in cationic biocides $[8,9]$. And many reports have demonstrated that QPS exhibit better antibacterial activity than QAS with the same structure except the cationic part [10].The fact is that QPS are weakly-associated cations compared with QAS due to the lower electronegativity of phosphorus than that of nitrogen [11], which facilitates QPS to adsorb more readily on negatively charged surface of microorganisms and kill them [12]. Along with the advantages like lower foam, higher stability and wider range of $\mathrm{pH}$ application ( $\mathrm{pH}$ values 2-12) than QAS, QPS therefore have great potential as new generation organic antimicrobials and have been actively applied as antibacterial component to fabricate various antibacterial materials, ranging from natural polymers (chitosan [13] and starch [14]), synthetic polymers such as polyacrylonitrile fiber [15] and polyacrylamide [16] to inorganic clay [17] as well as graphite [18]. Hence, it is expected that the introduction of QPS into polyurethane can impart antibacterial property to the matrix. However, to our best knowledge, the current information and reports concerning on the introduction of QPS into polyurethane polymer is very limited [19] and their approaches used to synthesize QPSbearing PU are very complicated, including several chemical reaction processes. Fabrication of a simple approach to incorporate QPS into PU is a challenging issue due to the lack of reactive groups in QPS structure.

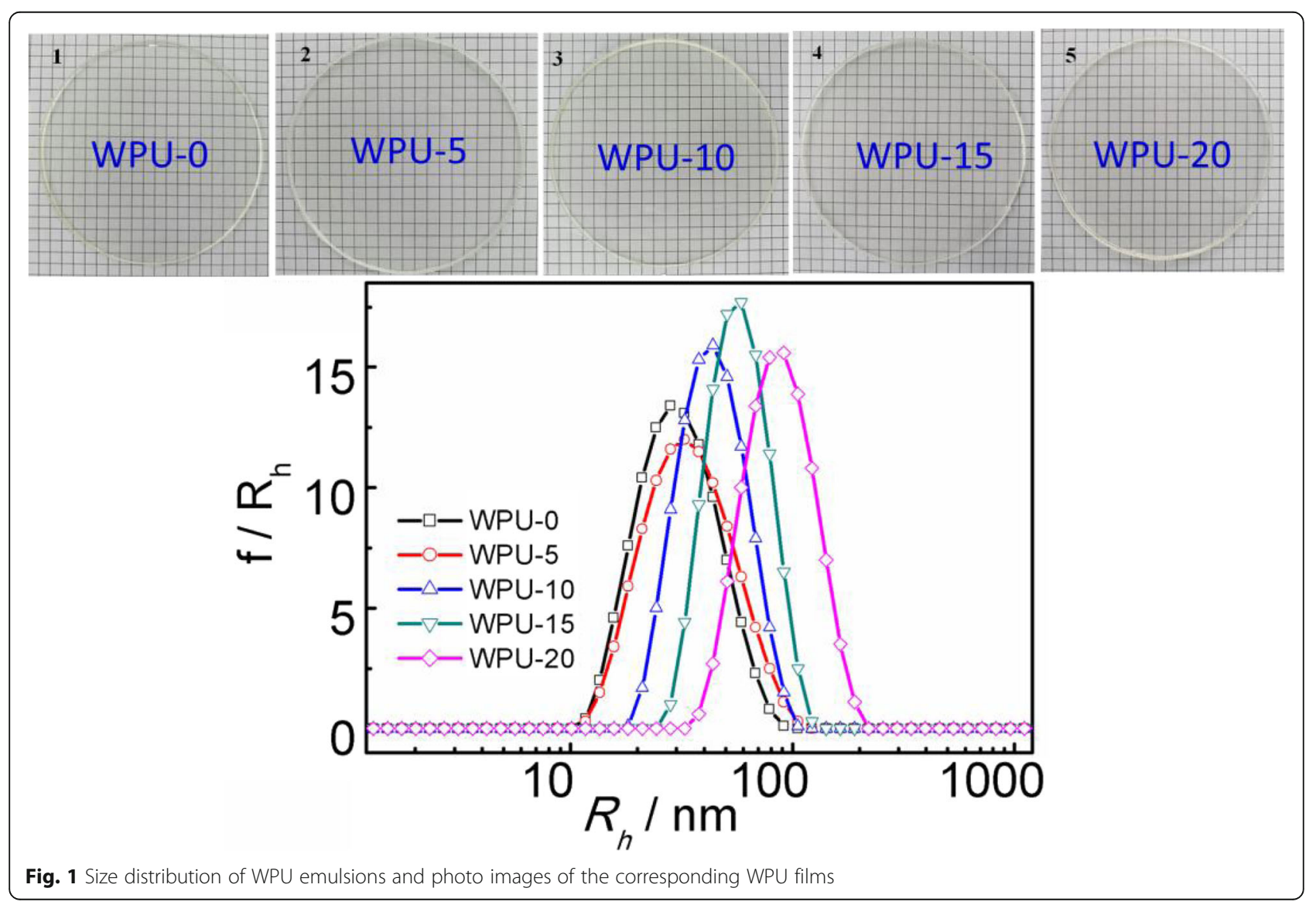



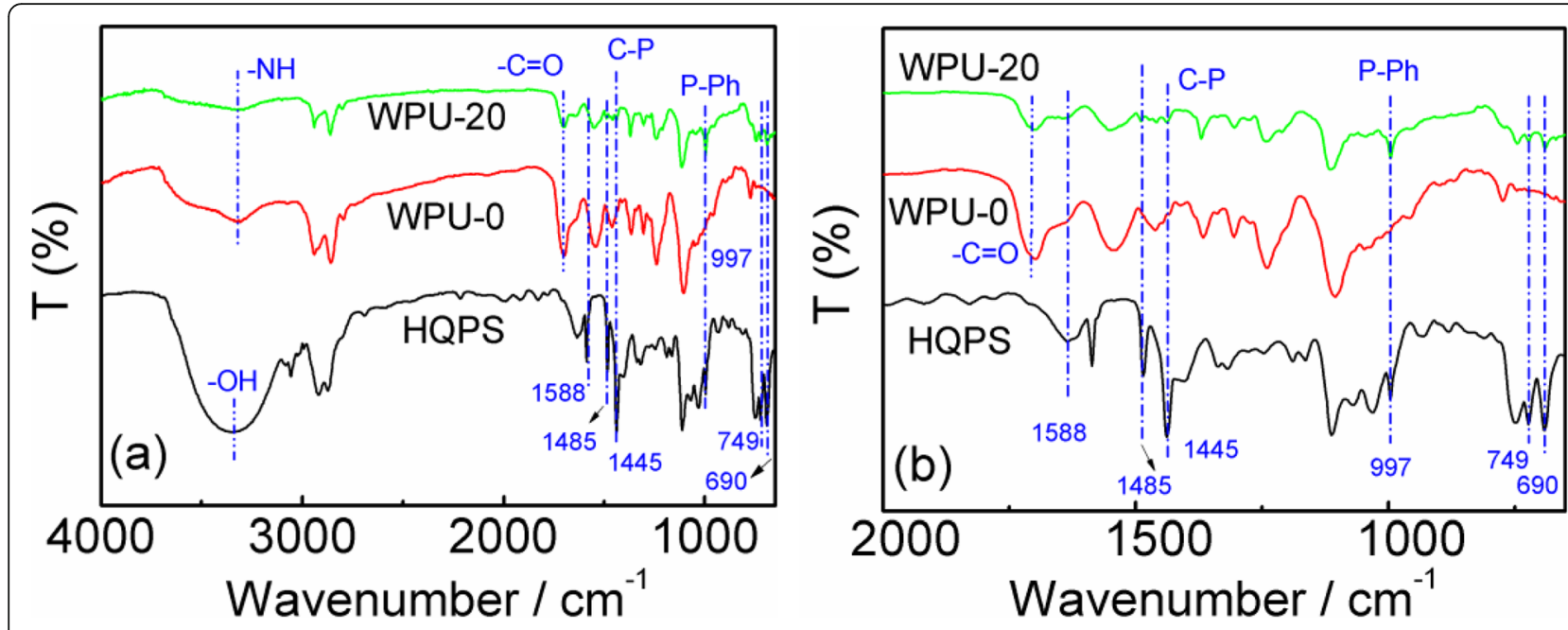

Fig. 2 FT-IR spectra of HQPS, WPU-0 and WPU-20: (a) whole spectra and (b) amplified spectra ranging from 600 to $2000 \mathrm{~cm}^{-1}$

In this study, we aimed at providing a facile approach to prepare non-leaching antimicrobial WPU with QPS groups. Allyltriphenyl-phosphonium bromide was functionalized with hydroxyl group through a thiol-ene Michael addition reaction so that the QPS groups can be introduced covalently into PU by polymerization reaction. The structures of polyurethane were characterized and their wettability, thermal stability and antibacterial effect were evaluated from different aspects.

\section{Experimental}

\subsection{Materials}

Peptone (BR), dibutyltin dilaurate (95\%), Allyltriphenylphosphonium bromide, Isophorone diisocyanate (IPDI), agar (BR), 2,3-Dihydroxypropanethiol (TPG), $\alpha, \alpha-$ Dimethoxy- $\alpha$-phenylacetophenone as well as beef extract were obtained from Aladdin. S. aureus (ATCC 6538)

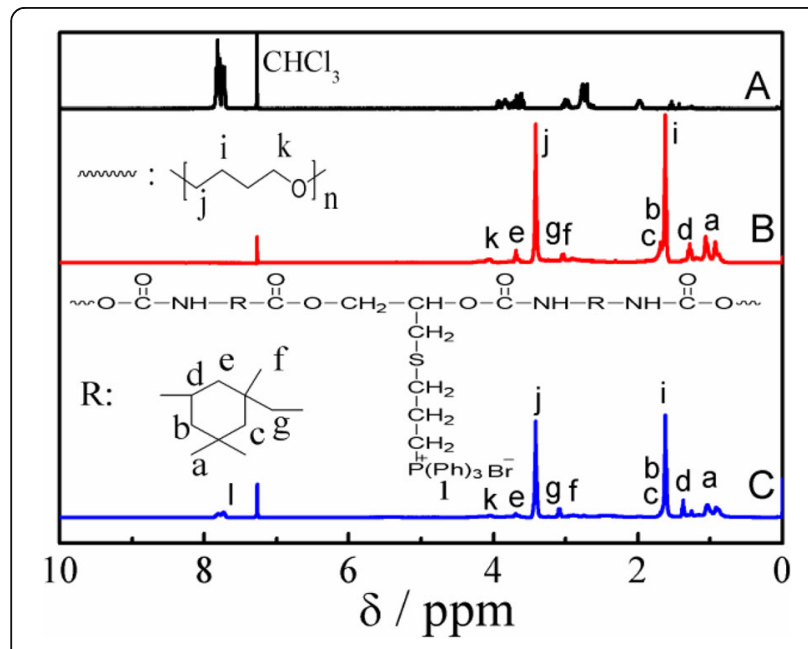

Fig. $3^{1} \mathrm{H}-\mathrm{NMR}$ spectra of (a) HQPS, (b) WPU-0 and (c) WPU-20 in $\mathrm{CDCl}_{3}$ and E. coli, (ATCC 25922) were provided by China Center of Industrial Culture Collection. 1,4-butylene glycol (1,4-BDO) was bought along with 2,2-Dimethylolpropionic acid (DMPA) from Aldrich. Poly (tetramethylene oxide) $(\mathrm{Mn}=2000 \mathrm{~g} / \mathrm{mol})$ from Aladdin was dehydrated before use.

\subsection{Synthesis of dihydroxy-terminated QPS (HQPS)}

Thiol-ene Michael addition reaction under UV radiation was proceeded to prepare HQPS with $\alpha, \alpha$-Dimethoxy- $\alpha$ phenylacetophenone as photoinitiator (Scheme 1), as our previous report [20]. Detailedly, QPS (3.83 g), TPG (2.16 $\mathrm{g})$, photoinitiator $(0.06 \mathrm{~g})$ along with $30 \mathrm{~mL}$ of dichloromethane were added into the reactor, respectively. After the removal operation of oxygen by degassing nitrogen into the reactor for $20 \mathrm{~min}$, the reactor was irradiated by a UV-lamp $\left(100 \mathrm{~mW} / \mathrm{cm}^{2}\right)$ for $30 \mathrm{~min}$. The wavelength of UV emitting was set at $350 \mathrm{~nm}$ and the light intensity was set at $50 \%$. The product underwent the purification process including precipitation into tetrahydrofuran (THF), filtration and drying $\left(40^{\circ} \mathrm{C}\right)$. The characterization of HQPS $(M w=446)$ has been systematically investigated in our previous report [20].

\subsection{Synthesis of QPS-bearing WPU}

Firstly, PU prepolymer were synthesized through the reaction between isocyanate group (-NCO) from IPDI and hydroxyl group $(-\mathrm{OH})$ from PTMG at $70{ }^{\circ} \mathrm{C}$ with DBTDL as catalyst with dry nitrogen as atmosphere for $1 \mathrm{~h}$ (Scheme 2). Then chain extenders including DMPA, HQPS, 1,4-BDO were introduced one after another and each reaction was kept at $80^{\circ} \mathrm{C}$ for $1 \mathrm{~h}$, respectively. After cooling to $40^{\circ} \mathrm{C}$, triethylamine was introduced and the neutralization process was kept for $0.5 \mathrm{~h}$. Finally, the deionized water was added into 

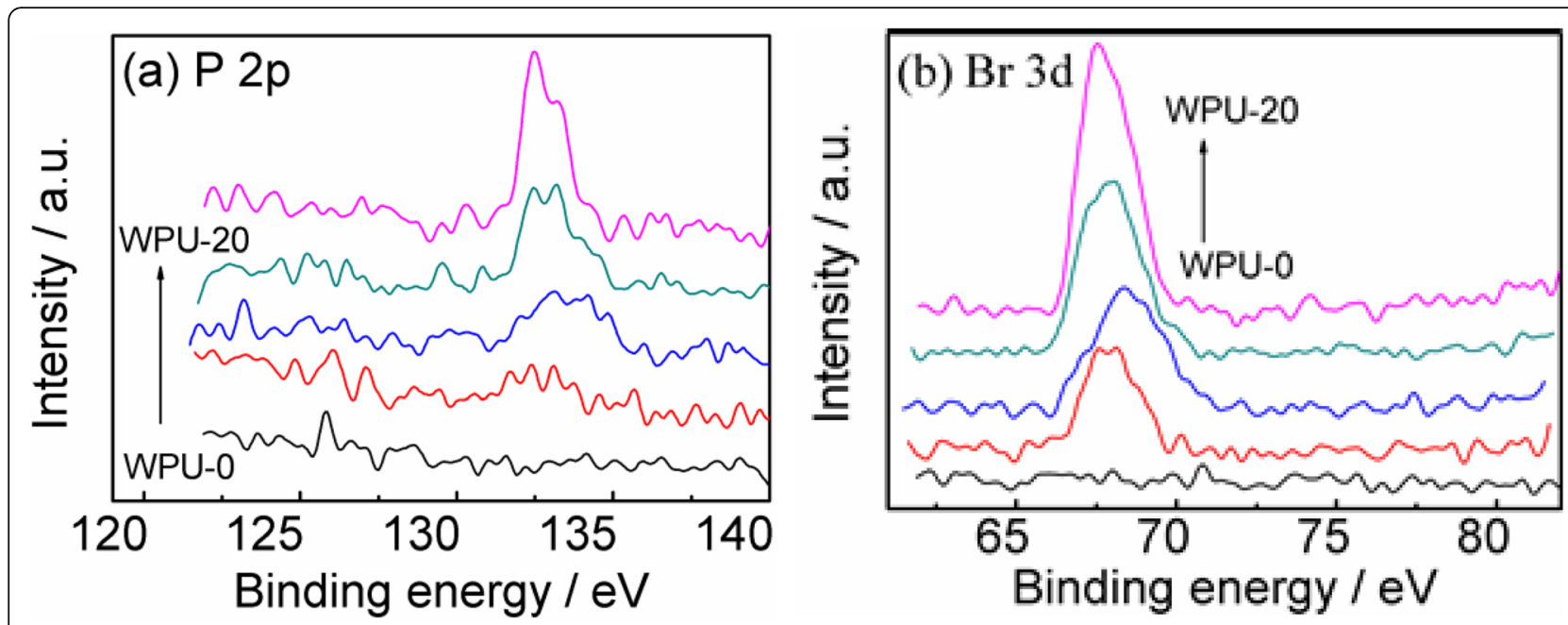

Fig. 4 XPS spectra of WPU: (a) P 2p; (b) Br 3d

condensate products and the emulsion proceeded for $20 \mathrm{~min}$ speed with a speed of $6000 \mathrm{rpm} / \mathrm{min}$ to obtain a series of WPU-X emulsions, where $\mathrm{X}$ is the weight percent of QPS in the WPU. The solid content of emulsions was $15 \%$. WPU-X films were obtained by drying quantitative emulsions in Polytetrafluoroethylene (PTFE) moulds at $40{ }^{\circ} \mathrm{C}$ until constant weight. Infrared Spectroscopy (IR): $3315 \mathrm{~cm}^{-1}(\mathrm{~N}-\mathrm{H}), 1725 \mathrm{~cm}^{-}$ ${ }^{1}(\mathrm{C}=\mathrm{O}), 1445 \mathrm{~cm}^{-1}\left(\mathrm{P}-\mathrm{CH}_{2}\right), 997 \mathrm{~cm}^{-1}(\mathrm{P}-\mathrm{Ph}), 749 \sim 690$, 1485 and $1588 \mathrm{~cm}^{-1}(\mathrm{Ph})$. Nuclear Magnetic Resonance (NMR): $\left(400 \mathrm{MHz}, \mathrm{CDCl}_{3}, \mathrm{ppm}\right): 1.01$ (a, $\left.\left(\mathrm{CH}_{2}\right)_{2} \mathrm{C}\left(\mathrm{CH}_{3}\right)_{2}\right), 1.35$ (d, $\left.\mathrm{NHCH}\left(\mathrm{CH}_{2}\right) \mathrm{CH}_{2}\right), 1.61$ (i, $\left.\mathrm{COCH}_{2} \mathrm{CH}_{2} \quad \mathrm{CH}_{2} \mathrm{CH}_{2} \mathrm{CH}_{2} \mathrm{O}\right), \quad 1.66$ (c, $\mathrm{CH}_{2}\left(\mathrm{CH}_{3}\right)$ $\left.\mathrm{CCH}_{2} \mathrm{C}\left(\mathrm{CH}_{3}\right)_{2} \mathrm{CH}_{2}\right), 1.68$ (b, $\left.\mathrm{CHCH}_{2} \mathrm{C}\left(\mathrm{CH}_{3}\right)_{2}\right), 2.91$ (f, $\left.\left(\mathrm{CH}_{2}\right)_{3} \mathrm{C}\left(\mathrm{CH}_{3}\right)\right), 3.08\left(\mathrm{~g}, \mathrm{OCOCH}_{2} \mathrm{C}\left(\mathrm{CH}_{3}\right) \mathrm{CH}_{2}\right), 3.42(\mathrm{j}$, $\left.\mathrm{COCH}_{2} \mathrm{CH}_{2} \mathrm{CH}_{2} \mathrm{CH}_{2} \mathrm{O}\right), 3.68$ (e, $\mathrm{NHCH}_{2} \mathrm{CH}_{2} \mathrm{C}(\mathrm{CH})_{3}$ $\left.\mathrm{CH}_{2}\right), \quad 4.02 \quad\left(\mathrm{k}, \quad \mathrm{COCH}_{2} \mathrm{CH}_{2} \mathrm{CH}_{2} \mathrm{CH}_{2} \mathrm{O}\right), \quad 7.5 \sim 7.9$ (l, $\left.\mathrm{P}\left(\mathrm{C}_{6} \mathrm{H}_{5}\right)_{3} \mathrm{Br}\right)$.

\subsection{Characterization methods}

\subsubsection{Size analysis}

The particle size of WPU dispersions with concentration of $1 \times 10^{-5} \mathrm{~g} / \mathrm{mL}$ was tested on a Malvern Zetasizer NanoZS (Marlvern, United Kingdom). Three replicate tests were carried out and the data was averaged for each emulsion.

\subsubsection{Fourier transform infrared spectroscopy (FTIR)}

Structure of HQPS and WPU were studied by a FT-IR spectrometer (Nicolet iS10 IR). The spectra were obtained by 64 scanning and the scanning range is $400 \sim$ $4000 \mathrm{~cm}^{-1}$.

\subsubsection{NMR spectroscopy}

The structure identification of HQPS and WPU was further conducted on a NMR spectrometer (Bruker AV II
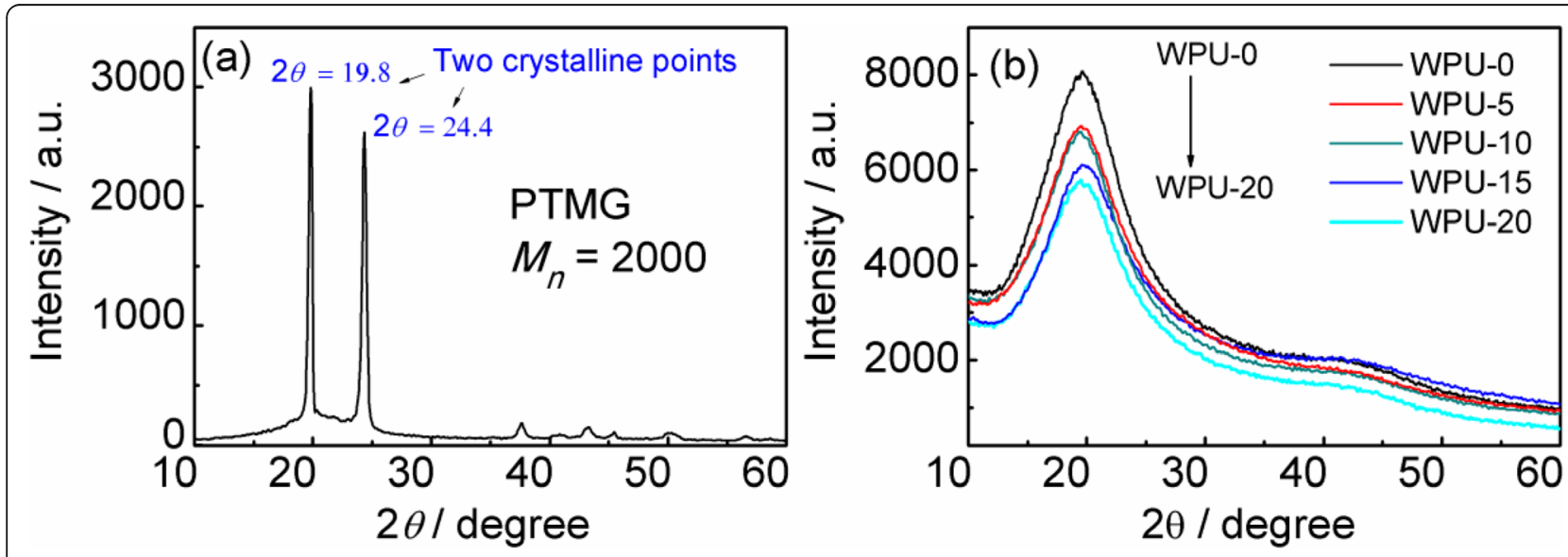

Fig. 5 (a) XRD patterns of PTMG and (b) all the WPU samples 


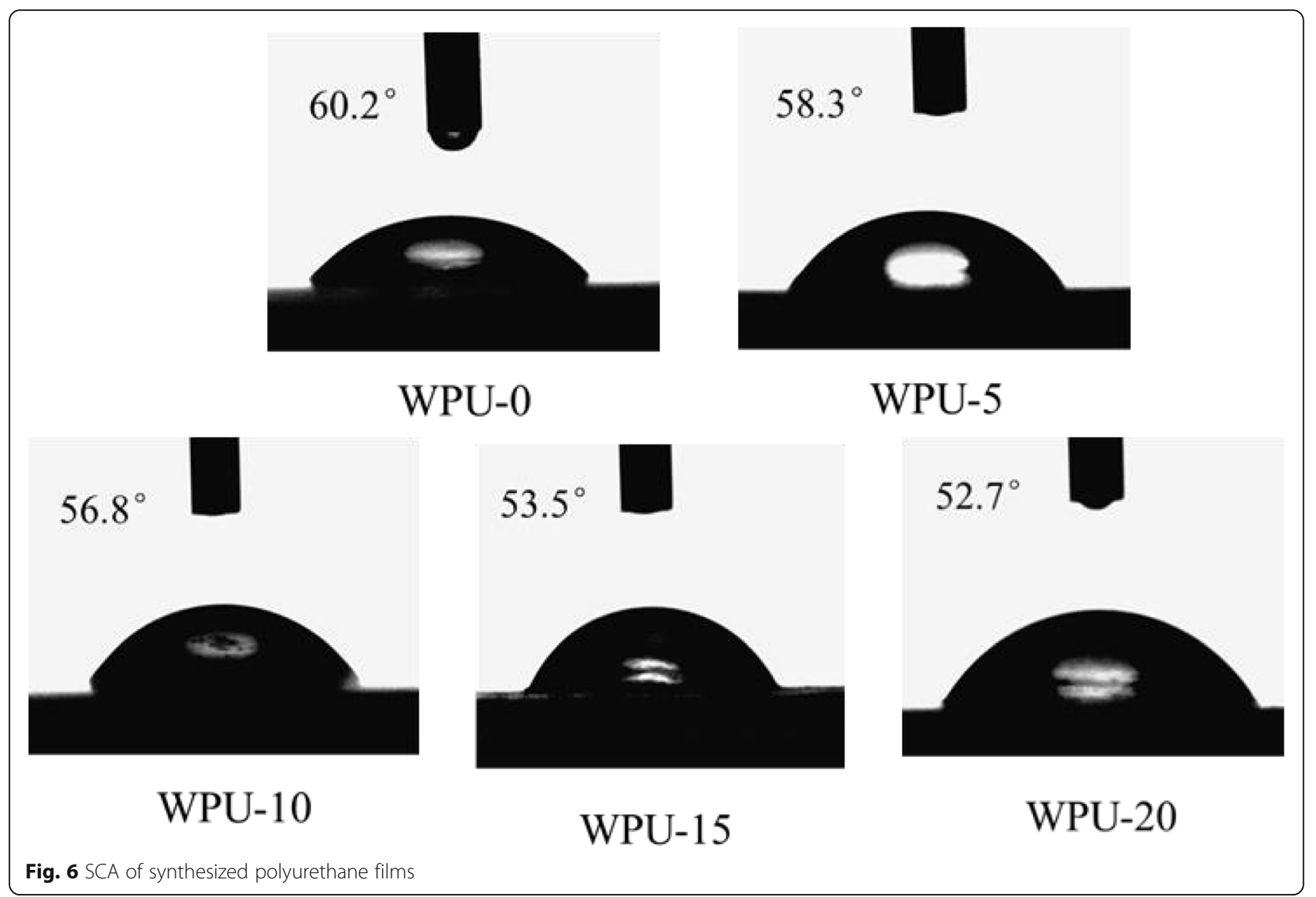

$400 \mathrm{MHz}$ ). The solvent used was $\mathrm{CDCl}_{3}$ and internal standard was tetramethylsilane (TMS).

\subsubsection{X-ray photoelectron spectroscopy (XPS)}

The presence of phosphorus $(\mathrm{P})$ atom and bromine $(\mathrm{Br})$ atom from HPQS in the WPU were detected by an XSAM 800 XPS spectrometer (Kratos, Britain) with the pressure of $10^{-9} \mathrm{mbar}$ in the sample chamber. The $\mathrm{x}$-ray source is $\mathrm{Al} \mathrm{K \alpha}(\mathrm{hv}=1486.6 \mathrm{eV})$.

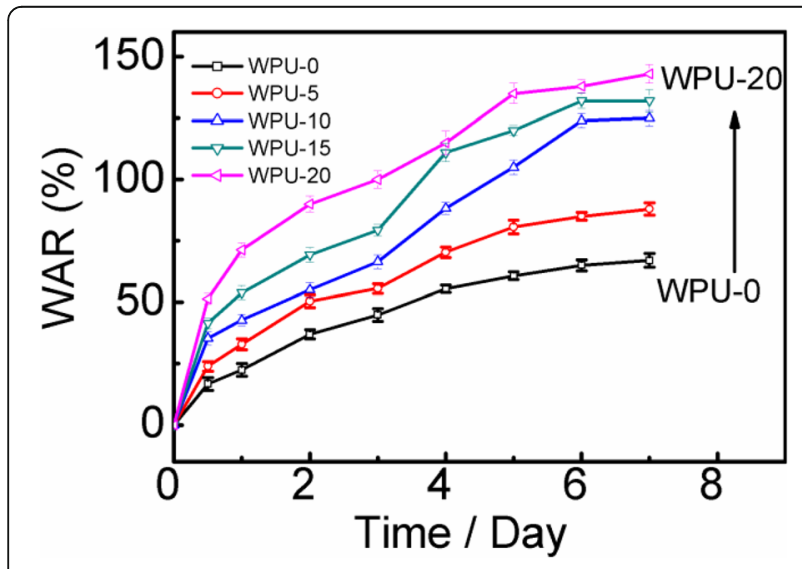

Fig. 7 WAR curves of the polyurethane films

\subsubsection{XRD analysis}

X-ray diffractometer (MXPAHF, Japan) was used for XRD investigation of WPU. The test was performed at ambient temperature by using $\mathrm{Cu} \mathrm{K}$ radiation and a detector at $10 \mathrm{~cm}$ distance. The radiation $\lambda$ is $0.154 \mathrm{~nm}$ and the scanning ranges from $10^{\circ}$ to $60^{\circ}$ and the scanning rate of was $2^{\circ} / \mathrm{min}$. The real lattice space $d$ was calculated by the formulation of $\lambda=2 d \sin \theta$ [21].

\subsubsection{Surface contact angle (SCA)}

The sample of WPU films was cut into slides with an area of $1 \mathrm{~cm} \times 3 \mathrm{~cm}$ and the SCA was measured on a Dataphysics OCAH 200 (Detaphysics, Germany). The average value was calculated from five replicates.

\subsubsection{Water absorption rate (WAR)}

Sample patches with areas of $1 \mathrm{~cm} \times 1 \mathrm{~cm}$ were soaked in distilled water and the weight of patches films before and after soaking as a function of time were recorded as $\mathrm{W}_{1}$ and $\mathrm{W}_{2}$, respectively. The WAR of films was calculated through the formulation of WAR $=\left(\mathrm{W}_{2}-\mathrm{W}_{1}\right) / \mathrm{W}_{1}$.

\subsubsection{TGA test}

The test was evaluated by a TG209F1 instrument under a heating rate of $10{ }^{\circ} \mathrm{C} / \mathrm{min}$. The used atmosphere was 


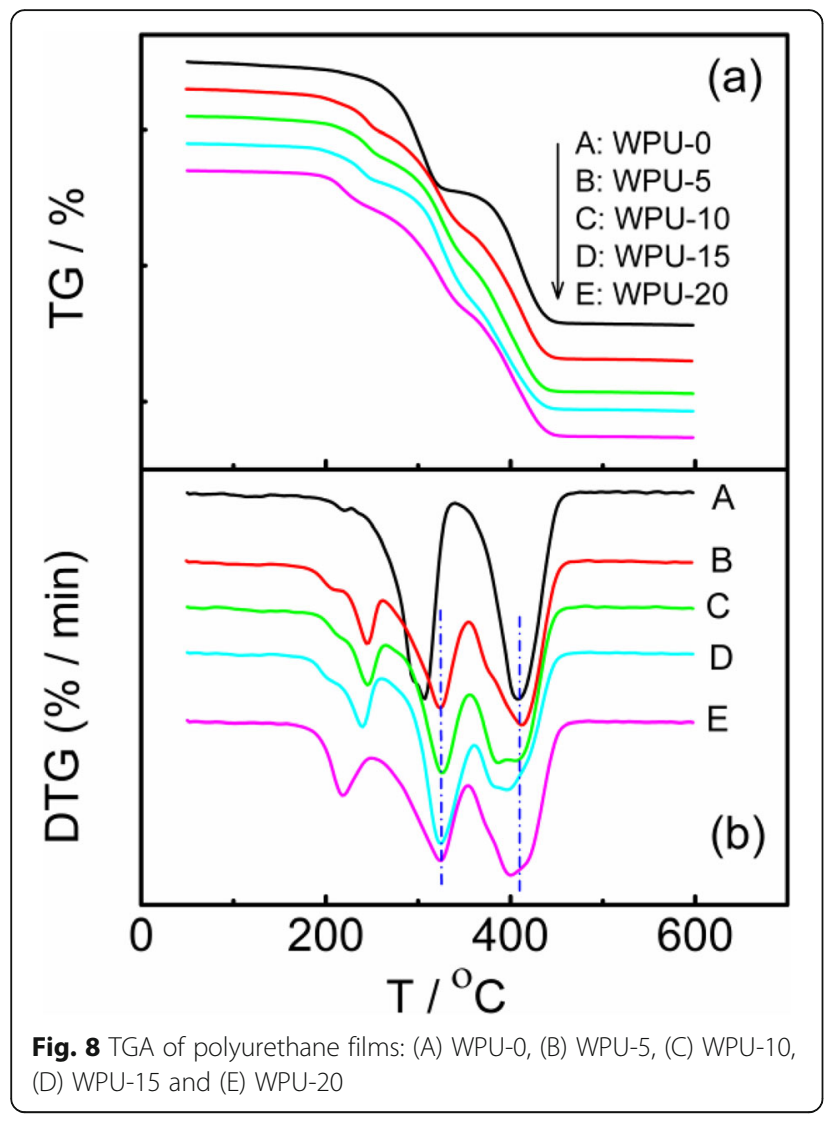

nitrogen and its flow rate was $20 \mathrm{~cm}^{3} / \mathrm{min}$. The scanning temperature was in the range of $50 \sim 600{ }^{\circ} \mathrm{C}$.

\subsection{Testing of antibacterial property}

Antibacterial tests were conducted by three methods as follows using $S$. aureus and $E$. coli as the test cultures. Before measurement, the fresh bacterial suspension of $E$. coli and $S$. aureus $\left(10^{7} \mathrm{CFU} / \mathrm{mL}\right)$ was prepared by using beef-protein liquid medium, respectively. The WPU films were sterilized by UV irradiation for $2 \mathrm{~h}$ before.

\subsubsection{Plate count method}

WPU disk with a diameter of $1 \mathrm{~cm}$ was added into erlenmeyer flask containing $70 \mathrm{~mL}$ PBS solutions and $5 \mathrm{~mL}$ bacterial suspension $\left(10^{7} \mathrm{CFU} / \mathrm{mL}\right)$. And the immersion process was kept at $24{ }^{\circ} \mathrm{C}$ for $18 \mathrm{~h}$ with continuous shaking $(150 \mathrm{rpm} / \mathrm{min})$. After completing inoculation with $100 \mu \mathrm{L}$ suspension onto the plate, incubation at $37^{\circ} \mathrm{C}$ was carried out and the incubation time was set as $24 \mathrm{~h}$. The value of bacterial inhibition ratio (BIR) [22] was calculated to evaluate the antibacterial effect of WPU. BIR $(\%)=\left(\mathrm{N}_{0}-\mathrm{N}_{\mathrm{X}}\right) / \mathrm{N}_{0} * 100 \%$, where $\mathrm{N}_{0}$ and $\mathrm{N}_{\mathrm{X}}$ represent the number of bacterial colonies of WPU-0 film and the number of bacterial colonies from the corresponding suspension in which WPU-X films were immersed. For each sample, four replicates were carried out.

\subsubsection{Fluorescence microscopy (FM)}

For the fluorescence study, a red dye (propidium iodide, PI) was used as fluorescence probe, as previous report [23]. PI is a dye which can penetrates compromised cytoplasmic membranes and thus fluoresces upon binding to nucleic acids [24]. Therefore, PI can mark the dead bacteria with emit red fluorescence. Each sterilized WPU-X film $(0.01 \mathrm{~g})$ was added into tubes containing bacterial suspension $(200 \mu \mathrm{L})$ and $1.8 \mathrm{~mL}$ of beef-protein liquid medium. After mixing, the whole tubes were placed at $37^{\circ} \mathrm{C}$ with mild shaking for $4 \mathrm{~h}$. Then the bacterial suspension of each tube $(200 \mu \mathrm{L})$ and $5 \mu \mathrm{L}$ of PI dye liquor were mixed and the mixture was kept for 20 min in the dark. The stained suspension was then examined using an inverted microscope (Olympus CKX 53, Japan) equipped with a mercury lamp and a long-pass filter. Excitation was carried out at $490 \mathrm{~nm}$ and emission wavelength was set at $635 \mathrm{~nm}$.

\subsubsection{Zone of inhibition experiment}

The experiment was conducted by following KirbyBauer disk diffusion analysis [24]. Active bacteria $(200 \mu \mathrm{L})$ were inoculated onto the agar plates and WPU films $(2 \mathrm{~cm}$ in diameter) were then placed onto thereafter. The incubation was kept at $37^{\circ} \mathrm{C}$ for $48 \mathrm{~h}$.

\section{Results and discussion}

The characterization data of the WPUs are shown in Table 1. Note that the presence of both hydrophilic cationic groups and hydrophobic benzene ring in QPS structure is very likely to affect the stability of WPU emulsion. Therefore, the dosage of DMPA is kept at 7 wt\% for all the WPU preparation, and subsequently the HQPS was introduced as chain extender to replace part of 1,4-BDO for the preparation of QPS-bearing WPU (Scheme 2). The content of hard segment (HS) in polyurethane is calculated according to the feed ratio. It varies from $52.3 \%$ for WPU-0 to $59.5 \%$ for WPU-20 because the HQPS has higher molecular weight $(\mathrm{Mw}=$ 446) than 1,4-BDO $(\mathrm{Mw}=90)$.

Figure 1 shows that the particle size of the emulsions gets larger with the increasing content of QPS, which can be related to the effect of the functional group. While the mean sizes of all the WPU emulsions are in the range of $28 \sim 80 \mathrm{~nm}$, thus transparent WPU films are resulted and good storage stability can be expected.

As shown in Fig. 2, the vibration peak of hydroxyl groups from HPQS disappears, and the vibration peak of $\mathrm{N}-\mathrm{H}$ group at $3315 \mathrm{~cm}^{-1}$ along with the vibration peak of $\mathrm{C}=\mathrm{O}$ group at $1725 \mathrm{~cm}^{-1}$ of polyurethane [25] occurs in FT-IR spectrum of WPU-20, demonstrating the incorporation of QPS into WPU. Moreover, the occurrence of new peaks observed in the spectrum of WPU20, i.e. absorptions at $997 \mathrm{~cm}^{-1}$ and $1445 \mathrm{~cm}^{-1}$ 

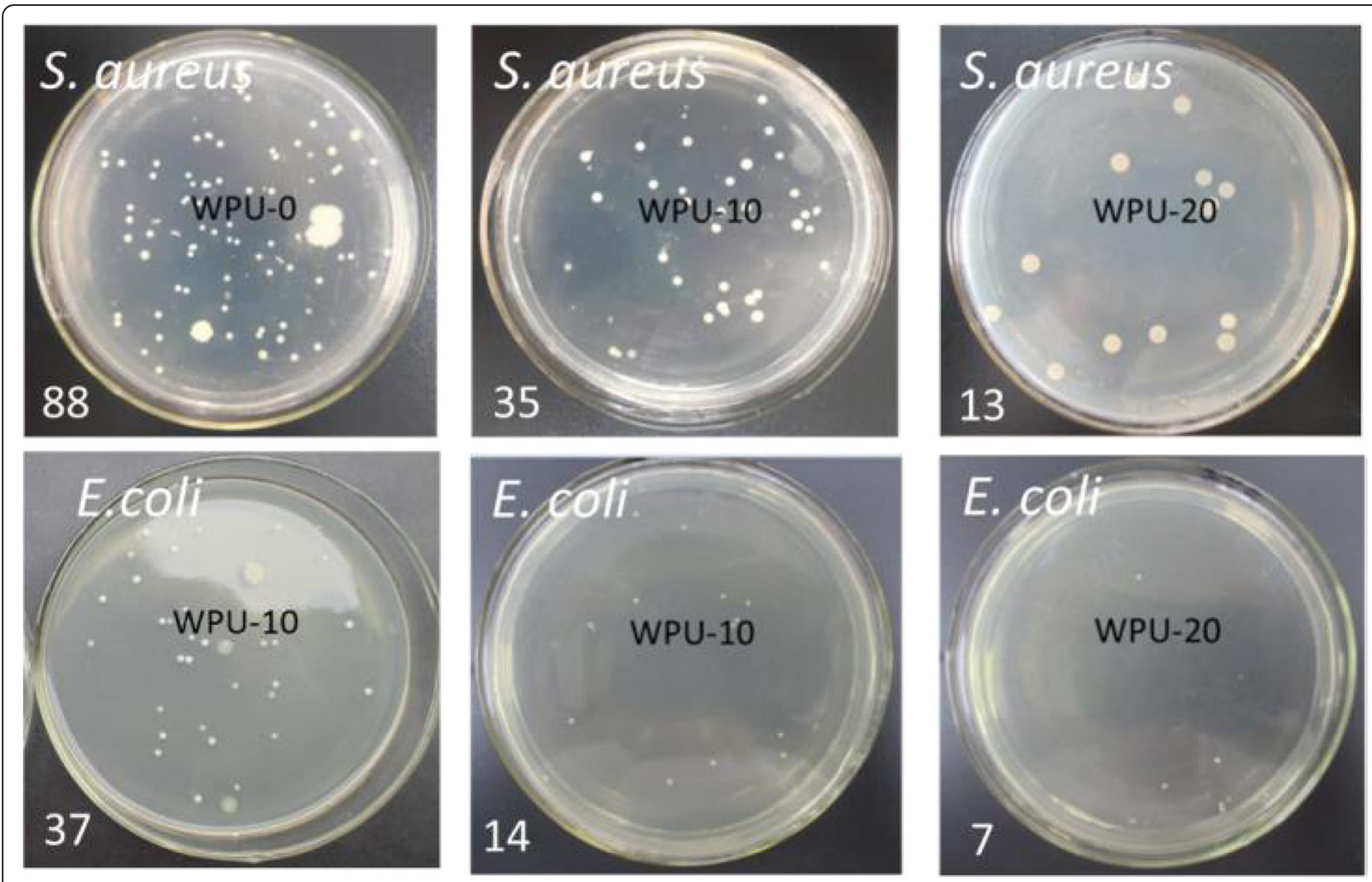

Fig. 9 Colony numbers S. aureus and E. coli from the bacterial suspensions (dilution ratio $=10^{7}$ ) after treatment with the polyurethane films for $18 \mathrm{~h}$
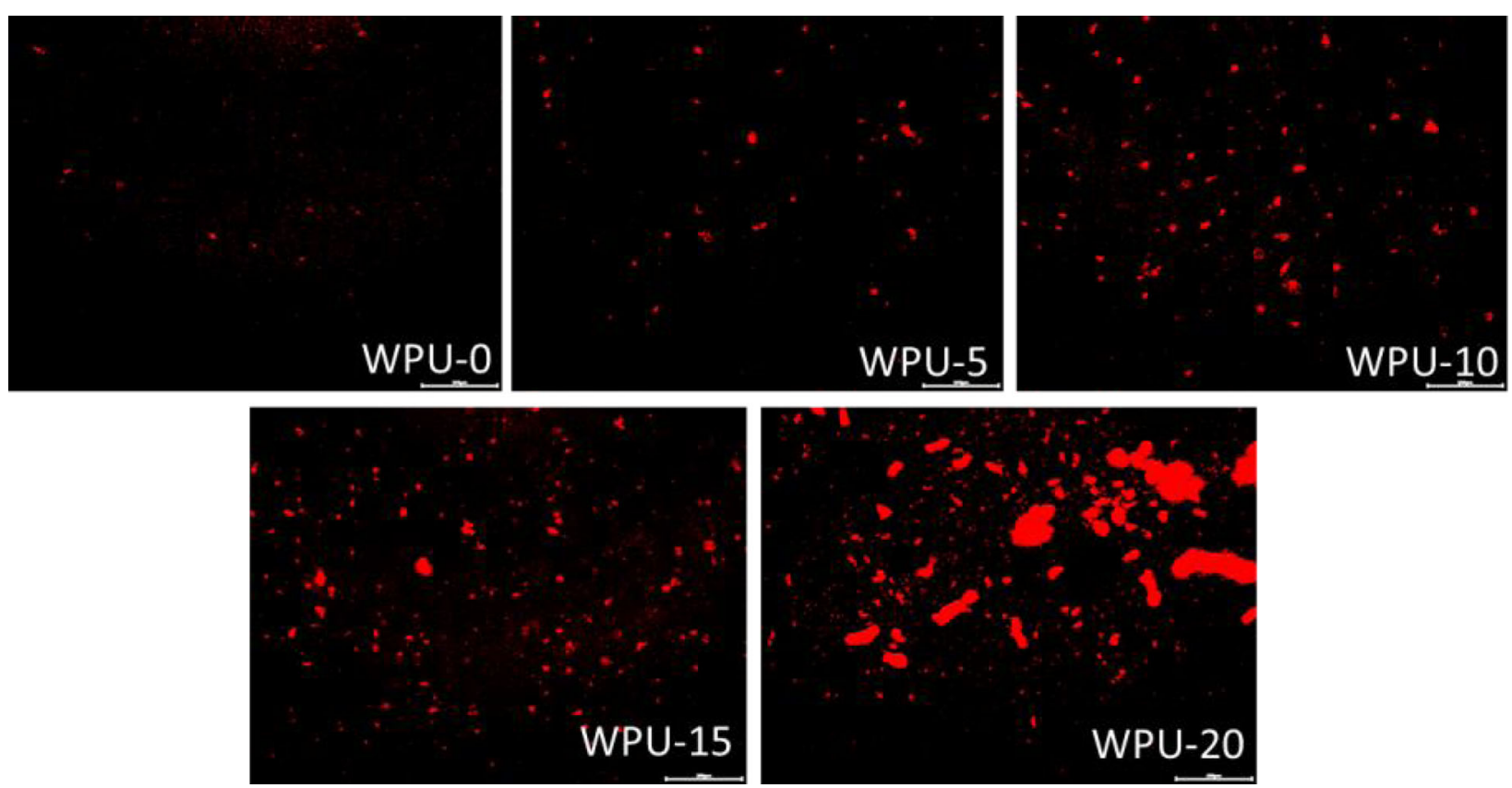

Fig. 10 FM images of S. aureus treated with WPU. The scale bar is $200 \mu \mathrm{m}$ 


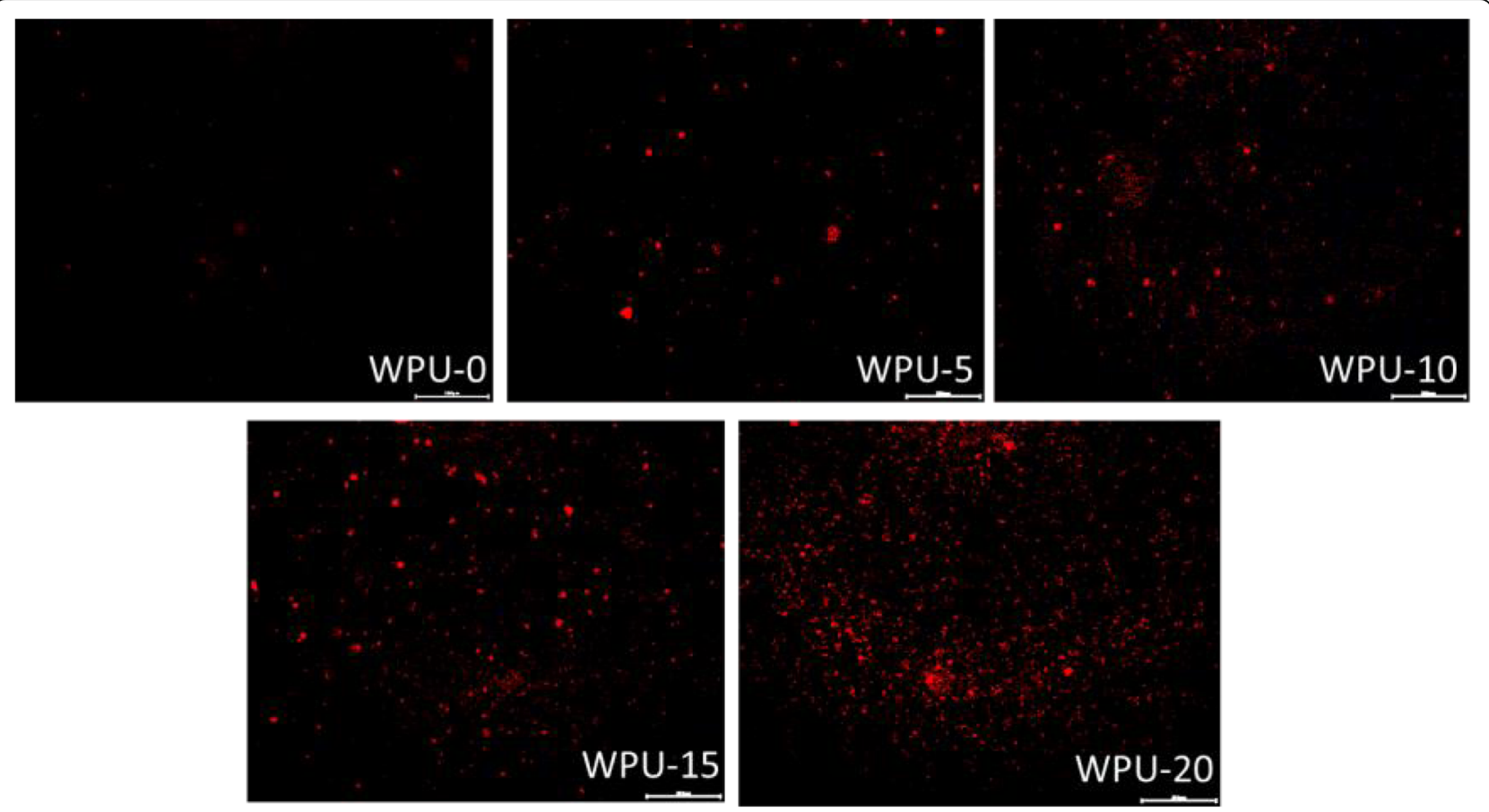

Fig. 11 FM images of E. coli suspension treated with WPU. The scale bar is $200 \mu \mathrm{m}$

corresponding to the vibration of $\mathrm{P}-\mathrm{Ph}$ and $\mathrm{P}-\mathrm{CH}_{2}$ groups respectively, along with the typical peaks of the benzene ring $\left(749 \sim 690,1485\right.$ and $\left.1588 \mathrm{~cm}^{-1}\right)$ further confirm the presence of QPS groups [26].

The ${ }^{1} \mathrm{H}$-NMR spectra of HQPS, WPU-0 and WPU-20 are exhibited in Fig. 3. The peak at 7.31 is assigned to the solvent $\mathrm{CDCl}_{3}$. For the typical ring structure of IPDI in WPU, the corresponding peaks appear at $\delta=1.01$ (a), 1.35 (d), 1.66 (c), 1.68 (b), 2.91 (f), 3.08 (g), and 3.68 (e) ppm. The peaks observed at $\delta=1.61$ (i), $3.42(\mathrm{j})$, and $4.02(\mathrm{k}) \mathrm{ppm}$ are attributed to the methylene units of
PTMG in both WPU-0 and WPU-20. Specifically for WPU-20, the occurrence of peaks at 7.5 7.9 (l) ppm attributed to the phenyl in HQPS [9] demonstrate the introduction of QPS moiety into polyurethane.

The P $2 \mathrm{p}$ and Br $3 \mathrm{~d}$ core level XPS spectra of WPU are collected in Fig. $4 \mathrm{a}$ and b, respectively. Except for WPU-0, a new peak at $132.5 \mathrm{eV}$ can be clearly observed in all the QPS-bearing WPUs, which corresponds to phosphorus nitrogen (2p) from HQPS [27]. And the peak intensity becomes stronger with the increasing quaternary phosphonium salt (QPS) groups. Fig. 4b show
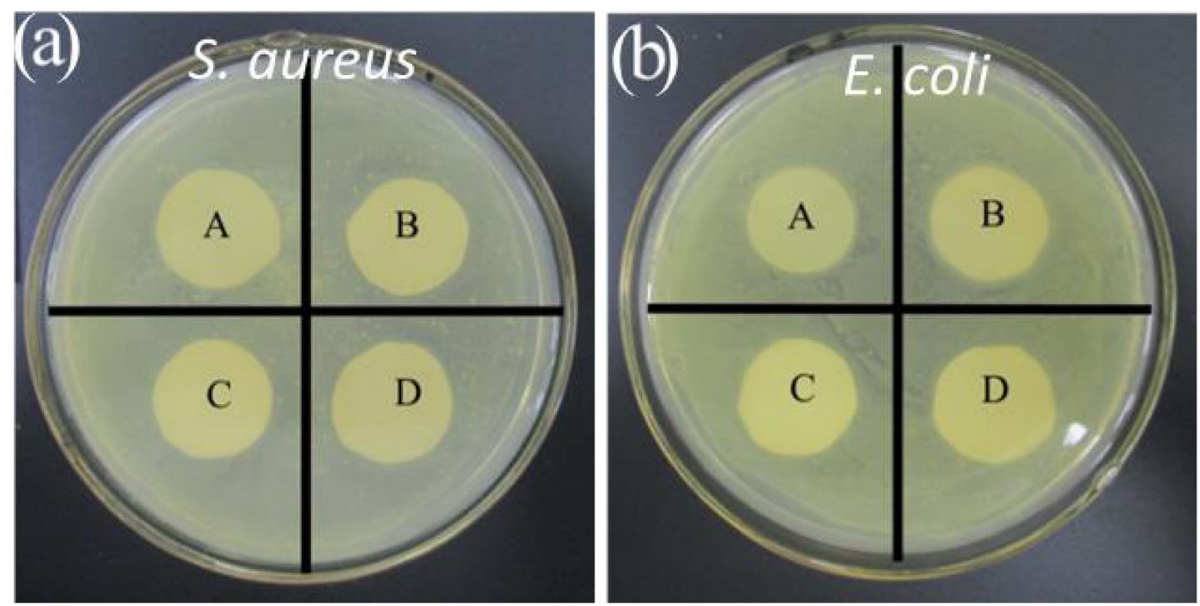

Fig. 12 The culture of S. aureus and E. coli on the synthesized polyurethane films: (A) WPU-0; (B) WPU-5; (C) WPU-10; (D) WPU-20 
XPS spectra corresponding to $\mathrm{Br} 3 \mathrm{~d}$ which is also from HQPS. Similarly, the expected peak at $68.2 \mathrm{eV}$ for $\mathrm{Br}$ atom appears [28] in all the QPS-bearing WPUs, and the corresponding peak intensity gets stronger at higher content of QPS, further indicating the presence of QPS groups in the WPU. The above FT-IR, NMR and XPS results demonstrate that the QPS groups can be facilely incorporated into WPU via thiol-ene addition reaction and polymerization reaction, more convenient than previously reported methods [19].

The XRD spectra of PTMG and WPUs are shown in Fig. 5. For the soft monomer PTMG, two sharp peaks with high intensity are observed at $2 \theta=19.8^{\circ}$ and $24.4^{\circ}$, indicating its crystalline characteristic [29]. As to the resulting WPUs, only a broad peak around $2 \theta=20.4^{\circ}$ is observed, indicating its amorphous structure [30]. The peak intensities become weaker at higher content of QPS, revealing that the introduction of QPS moiety into polyurethane affects the ordered arrangement of polyurethane chains. The reason can be that compared with the chain extenders 1,4-BDO, the introduced QPS has more irregular structures. As QPS content increases in WPU, the content of 1,4-BDO decreases accordingly. In addition, the steric hindrance of ring structure in QPS may exert adverse effect on the formation of ordered arrangement, thus disrupting the crystallization capacity of the polyurethane chains [31, 32].

As shown in Fig. 6, the SCA values are reduced with increasing content of QPS, ranging from $52.7^{\circ}$ to $60.2^{\circ}$. It indicates that the incorporation of QPS leads to the reduced surface hydrophobicity of WPU films to some degree. Regarding the importance of the water resistance for coating materials, the kinetics curves of water absorption rate (WAR) of WPU films are plotted in Fig. 7. It shows that the WAR values increase with the increasing contents of QPS, and the water resistance of the films apparently decrease during long time soaking. We initially expected that the cyclic (benzene ring) structures of QPS would be favorable for enhancing the hydrophobicity of WPU films, as proved in our previous study [33]. However, both of SCA and WAR results show that the stronger hydration of cationic groups in QPS cannot be neglected. Further work is needed to improve the water resistance of the synthesized antibacterial WPU for the purpose of leather coatings by the control the ratio of hydrophobic benzene rings and hydrophilic cationic groups in QPS structure.

TGA results of WPU are shown in Fig. 8. Two main thermal peaks at 320 and $410^{\circ} \mathrm{C}$ appear for all the WPUs, representing the decomposition of HS and SS of PU, respectively [34]. For QPS-bearing WPUs like WPU-5, a new but small peak is observed clearly at $245^{\circ} \mathrm{C}$. The peak shifts to lower temperature $\left(217^{\circ} \mathrm{C}\right.$ for WPU-20) with the increasing content of QPS, revealing that the introduction of QPS slightly reduces the thermal stability of WPU. It is reasonable because the bond energy of $\mathrm{C}-\mathrm{S}$ bond is weaker than that of $\mathrm{C}-\mathrm{C}$ bond [35, 36], and thus the C-S bond in QPS cause the decrease of the thermal dissociation temperature. Nevertheless, the high thermal stability of QPS-bearing WPU can meet the demand of leather finishing as film-forming materials.

The results of plate count experiments are shown in Fig. 9. The colony numbers of visible Gram-positive bacterium $S$. aureus on the polyurethane films WPU-0, WPU- 10 and WPU-20 are 88, 35 and 13 units, respectively. The inhibition rate of WPU-20 is up to $85 \%$. As to the resistance against Gram-negative bacterium E. coli, a slightly lower inhibition ratio $(81 \%)$ was obtained by the same counting method. The results indicate that WPU films with QPS groups exhibit broad-spectrum antibacterial activity and inhibit the growth of $S$. aureus (Grampositive bacteria) to a greater extent.

Fluorescence microscopy (FM) was also used as an alternative and non-invasive technique to evaluate bactericidal effect of materials. The PI dye is nucleic acid stains and only dead bacteria with damaged membranes can be stained. Thus in the FM images, the larger area covered by red fluorescence corresponds to more dead bacteria $[24,37,38]$. FM images of $S$. aureus suspension treated with WPUs are depicted in Fig. 10. Compared with WPU-0, a larger quantity of dead bacteria are obseved in the suspension treated with WPU-20. It suggests that the functionalized WPU films at higher content of QPS have better bactericidal effect against $S$. aureus.

Figure 11 shows FM images of $E$. coli suspension treated with WPU. Like the results of $S$. aureus, for QPS-bearing WPU samples, the corresponding area of red fluorescence, i.e. the number of dead $E$. coli bacterial cell rises gradually with the increasing content of QPS, revealing the enhanced antibacterial activity.

Over all, the above antibacterial tests indicate that the QPS-bearing WPUs exhibit good bacteriostatic action and their antimicrobial property increases with the increasing content of QPS. In comparison to its antibacterial activity against E. coli, WPU functionalized with QPS was found to be more bactericidal against $S$. aureus as demonstrated by higher bacteriostatic rate and larger cover area of dead bacteria dominating the fluorescent images, which is consistent with previous reports [16]. The inner antibacterial mechanism of QPS has been most widely explored. It is believed that QPS groups can disrupt the integrity of bacterial membranes, resulting in the leakage of intracellular components from bacterial cells [12]. The bacteriostatic action of the functionalized WPU is attributed to the biocidal nature of the introduced QPS moiety.

For further studying the potential leaching of biocidal moieties of QPS from WPU materials, zone of inhibition 
experiment were further performed. The inhibiting ability of biocidal moiety against the growth of microbe where it contacts the plate represents its bacteriostatic activity. Typically, antimicrobial small molecule compounds tend to diffuse on the agar plate, subsequently bringing about the concentration gradient of the antimicrobial molecules and a zone of inhibition surrounding the antimicrobial-rich areas. Therefore, the leaching of QPS from polyurethanes can be studied by detecting the area around the polyurethane films that is free of bacteria [21]. As shown in Fig. 12, no inhibition zones were observed for QPS-bearing WPUs after $48 \mathrm{~h}$ incubation, indicating that introduced biocidal QPS in the polyurethane matrix will not migrate from WPU into the surrounding environment. It implies that the synthesized QPS-bearing WPU by designed approach is a nonleaching antimicrobial material.

\section{Conclusion}

In conclusion, a novel QPS-bearing WPU leather coating was prepared via a facile approach as proved by FTIR, ${ }^{1} \mathrm{H}$-NMR and XPS. The thermal stability of the WPU is decreased slightly with the increasing content of QPS. The hydrophility of QPS-bearing WPU with higher content of QPS is stronger, thus the water resistance of the films needs to be improved for leather coatings. Antibacterial evaluations demonstrate that with the increase of efficiently introduced QPS, the as-prepared WPU films exhibit enhanced antibacterial activity and no leaching trends exist based on the zone of inhibition experiment. Regarding the risk and restrictions on the use of bactericides in the leather coatings, the non-leaching antimicrobial surfaces are becoming more attractive. Hence, the WPU with covalently-bound QPS by the designed approach is a non-leaching antimicrobial coating, inhibiting the growth of microbe onto leather.

\begin{abstract}
Abbreviations
1,4-BDO: 1,4-butylene glycol; $\mathrm{CDCl}_{3}$ : Chloroform-d; DBTDL: dibutyltin dilaurate; DMPA: 2,2-Dimethylolpropionic acid; FM: Fluorescence microscopy; FTIR: Fourier Transform Infrared Spectroscopy; HQPS: Dihydroxy-terminated QPS; HS: Hard segments; IPDI: Isophorone diisocyanate; NMR: Nuclear Magnetic Resonance Spectroscopy; PI: Propidium iodide; PTMG: Poly (tetramethylene oxide); PU: polyurethane; QPS: Quaternary phosphonium salts; SCA: Surface Contact Angle; TGA: Thermogravimetric Analysis; TPG: 2,3Dihydroxypropanethiol; WAR: Water Absorption Rate; WPU: Waterborne polyurethane; XRD: X-ray Diffraction
\end{abstract}

\section{Acknowledgements}

We appreciated the support from Dr. Lingyu Yu for providing the information on the material safety data sheet of three kinds of quaternary phosphonium salt (QPS), including the allyltriphenylphosphonium bromide used in the study.

\section{Authors' contributions}

CW was a major contributor in designing and performing the experiments, and writing the manuscript. LL performed the antibacterial test of polyurethane coating films. JW interpreted the chemical structure of polyurethane. $C M$ revised this manuscript and $\mathrm{WL}$ proposed the scientific idea, the methods used in this study. All authors read and approved the final manuscript.

\section{Funding}

The support from Innovation Team Program of Science and Technology (2017TD0010), Key research and development project (2018GZ031518) of Sichuan Province, China Postdoctoral Science Foundation (2018 M631083, 2019 T120842), and postdoctoral research and development Foundation of Sichuan University (2019SCU12060) are gratefully acknowledged.

\section{Availability of data and materials}

All data from this study are presented in the paper.

\section{Competing interests}

The authors declare that they have no competing interests.

Received: 3 June 2019 Accepted: 1 November 2019

Published online: 16 January 2020

\section{References}

1. Xu H, Ning H, Chen Y, Fan HJ, Shi B. Sulfanilamide-conjugated polyurethane coating with enzymatically-switchable antimicrobial capability for leather finishing. Prog Org Coat. 2013;76(5):924-34.

2. Chen Y, Fan HJ, Shi B. Nanotechnologies for leather manufacturing: a review. J Am Leather Chem Ass. 2011;106(8):260-73.

3. European Directive, 2009/251/EC, Commission Decision of 17 , Official Journal of the European Union. 2009. p. L 74/32-34.

4. Martins SE, Fillmann G, Lillicrap A, Thomas KV. Review: ecotoxicity of organic and organo-metallic antifouling co-biocides and implications for environmental hazard and risk assessments in aquatic ecosystems. Biofouling. 2018;34(1):34-52.

5. Kugel A, Stafslien S, Chisholm BJ. Antimicrobial coatings produced by "tethering" biocides to the coating matrix: a comprehensive review. Prog Org Coat. 2011;72(3):222-52.

6. Chang JM, Yang GF, Zeng Q, Xu Z, Chen Y, Fan HJ. Poly(N-Acryloyl ciprofloxacin-co-acrylic acid)-incorporated waterborne polyurethane leather coating with long-lasting antimicrobial property. J Am Leather Chem Ass. 2017;112(1):15-22

7. Zhang Y, He X, Ding M, He W, Li J, Tan H. Antibacterial and biocompatible crosslinked waterborne polyurethanes containing gemini quaternary ammonium salts. Biomacromolecules. 2018;19:279-87.

8. Chen Y, Tan W, Li Q, Dong F, Gu G, Guo Z. Synthesis of inulin derivatives with quaternary phosphonium salts and its antifungal activity. Int J Biol Macromol. 2018:113:1273-8.

9. Anthierens T, Billiet L, Devlieghere F, Prez FD. Poly (butylene adipate) functionalized with quaternary phosphonium groups as potential antimicrobial packaging material. Innov Food Sci Emerg. 2012;15:81-5.

10. Guo A, Wang F, Lin W, Xu X, Tang T, Shen Y, Guo S. Evaluation of antibacterial activity of $\mathrm{N}$-phosphonium chitosan as a novel polymeric antibacterial agent. Int J Biol Macromol. 2014;67:163-71.

11. Muñoz-Bonilla A, Fernández-García M. Polymeric materials with antimicrobial activity. Prog Polym Sci. 2012;37:281-339.

12. Xue $Y$, Pan $Y$, Xiao $H$, Zhao $Y$. Novel quaternary phosphonium-type cationic polyacrylamide and elucidation of dual-functional antibacterial/antiviral activity. RSC Adv. 2014:4:46887-95.

13. Zhu D, Cheng H, Li J, Zhang W, Chen S. Enhanced water-solubility and antibacterial activity of novel chitosan derivatives modified with quaternary phosphonium salt. Mat Sci Eng C. 2016;61:79-84.

14. Tan W, Li Q, Wei L, Wang P, Gao Z, Chen Y, Dong F, Guo ZY. Synthesis, characterization, and antifungal property of starch derivatives modified with quaternary phosphonium salts. Mat Sci Eng C. 2017;76:1048-56.

15. Chang L, Zhang X, Shi X, Zhao L, Liu X. Preparation and characterization of a novel antibacterial fiber modified by quaternary phosphonium salt on the surface of polyacrylonitrile fiber. Fiber Polym. 2014;15(10):2026-31.

16. Xue $Y, X i a o H$. Characterization and antipathogenic evaluation of a novel quaternary phosphonium tripolyacrylamide and elucidation of the inactivation mechanisms. J Biomed Mater Res A. 2016;104(3):747-57.

17. Cai X, Zhang J, Ouyang Y, Ma D, Tan S, Peng Y. Bacteria-adsorbed palygorskite stabilizes the quaternary phosphonium salt with specifictargeting capability, long-term antibacterialactivity, and lower cytotoxicity. Langmuir. 2013;29(17):5279-85. 
18. Xie AG, Cai X, Lin MS, Wu T, Zhang XJ, Lin ZD, Tan SZ. Long-acting antibacterial activity of quaternary phosphonium salts functionalized fewlayered graphite. Mat Sci Eng B. 2011;176(15):1222-6.

19. Guo L, Zhang L, Wang Y, Wu J. Study of synthesis and characterization of antibacterial polyurethane-acrylate. Eng Plastics Appl. 2011;39(4):26-7.

20. Li L, Wang CH, Zhu YK, Lin W. Synthessis and antibacterial activity characterization of a hydroxyl quatemary phosphonium salt. China Leather. 2017:46(12):10-5.

21. Ahmadi B, Kassiriha M, Khodabakhshi K, Mafi ER. Effect of nano layered silicates on automotive polyurethane refinish clear coat. Prog Org Coat. 2007:60:99-104

22. Chen SG, Chen SJ, Jiang S, Xiong ML, Luo JX, Tang JN, Ge ZC Environmentally friendly antibacterial cotton textiles finished with siloxane sulfopropylbetaine. ACS Appl Mater Interfaces. 2011;3:1154-62.

23. Hoque J, Akkapeddi P, Yarlagadda V, Uppu DSSM, Kumar P, Haldar J. Cleavable cationic antibacterial amphiphiles: synthesis, mechanism of action, and cytotoxicities. Langmuir. 2012;28(33):12225-34.

24. Anantharaman A, Sahal D. Reverse engineering truncations ofan antimicrobial peptide dimer to identify the origins of potency and broad spectrum of action. J Med Chem. 2010;53:6079-88.

25. Wang C, Ma C, Mu C, Lin W. Tailor-made zwitterionic polyurethane coatings: microstructure, mechanical property and their antimicrobial performance. RSC Adv. 2017;7(44):27522-9.

26. Kenawy ER, Abdel-Hay Fl, El-Magd AA, Mahmoud Y. Biologically active polymers: vii. Synthesis $t$ antimicrobial activity of some crosslinked copolymers with quaternary ammonium and phosphonium groups. React Funct Polym. 2006;66(4):419-29.

27. Crist BV. Handbook of monochromatic XPS spectra, the elements and native oxides, XPS International Inc; 2000.

28. Demchenko P, Khyzhun OY, Fochuk PM, Levkovets SI, Myronchuk GL, Parasyuk OV. Single crystal growth, structure and properties of $\mathrm{TlHgBr}_{3}$. Opt Mater. 2015;49:94-9.

29. Sadeghi M, Semsarzadeh MA, Barikani M, Ghalei B. The effect of urethane and urea content on the gas permeation properties of poly (urethane-urea) membranes. J Mem Sci. 2010;354(1):40-7.

30. Billmeyer WF. Textbook of Polymer Science. 3rd ed. New York: Wiley; 1984 p. 238-90.

31. Lei W, Shen Y, Lai X, Li Z, Min L. Synthesis and properties of crosslinked waterborne polyurethane. J Polym Res. 2011;18(3):469-76.

32. Zhou $Y$, Huang $X$, Tang $X$. Synthesis and characterization of novel thermoplastic poly (oligophosphazene-urethane)s. Polym Int. 2010;58(6): 710-4.

33. Wu JH, Wang $\mathrm{CH}, \mathrm{Mu} C \mathrm{CD}$, Lin W. A novel waterborne polyurethane coating functionalized by Isobornyl acrylate with enhanced antibacterial adhesion and hydrophobic property. Eur Polym J. 2018;108:498-506.

34. Cervantes-Uc JM, Moo Espinosa JI, Cauich-Rodríguez JV, Avila-Ortega A, Vázquez-Torres H, Marcos-Fernández A, San RJ. TGA/FTIR studies of segmented aliphatic polyurethanes and their nanocomposites prepared with commercial montmorillonites. Polym Degrad Stab. 2009;94(10):166677.

35. And MM, Golden DM. Hydrocarbon bond dissociation energies. Ann Rev Phys Chem. 1982;33(33):493-532.

36. Kim SM, Park SA, Hwang SY, Kim ES, Egal J, Im CH, Jeon H, Oh DX, Park J. Environmentally-friendly synthesis of carbonate-type Macrodiols and preparation of transparent self-healable thermoplastic polyurethanes. Polymers. 2017;9(12):663-78.

37. Sun X, Qian Z, Luo L, Yuan Q, Guo X, Tao L, Wei Y, Wang X. Antibacteria adhesion of polymethyl methacrylate modified by borneol acrylate. ACS Appl Mater Interfaces. 2016:8:28522-8.

38. Grapski JA, Cooper SL. Synthesis and characterization of non-leaching biocidal polyurethanes. Biomaterials. 2001:22(16):2239-46.

\section{Publisher's Note}

Springer Nature remains neutral with regard to jurisdictional claims in published maps and institutional affiliations.

\section{Submit your manuscript to a SpringerOpen ${ }^{\circ}$ journal and benefit from:}

- Convenient online submission

- Rigorous peer review

- Open access: articles freely available online

- High visibility within the field

- Retaining the copyright to your article

Submit your next manuscript at $\boldsymbol{\nabla}$ springeropen.com 